\title{
Chemotactic Function in the Human Neonate: Humoral and Cellular Aspects
}

\author{
Michael E. Miller ${ }^{[36]}$ \\ University of Pennsylvania School of Medicine, and Laboratory of Clinical Immunology, \\ Children's Hospital of Philadelphia, Philadelphia, Pennsylvania, US $\Lambda$
}

\section{Extract}

The cellular and humoral components of the chemotactic response in neonates have been compared with those in adults.

Leukocytes from neonates were compared with those from adults in their ability to move toward chemotactic factors (CF) generated from pooled, normal serum. Neonatal leukocytes showed a consistent and highly significant deficiency in their response to chemotactic factor generated from Staphylococcus aureus, Escherichia coli, or albuminantialbumin (Table I).

Chemotactic factor generated from neonatal and adult sera was compared for its ability to stimulate migration of a standardized, normal leukocyte pool. A small but highly significant difference was seen between the amounts of effective CF generated from neonatal sera and that from adult sera. The difference was found with all three generating agents (Table II).

The mechanism by which leukocytes undergo chemotactic migration is presently unclear. It is possible that in neonates cellular defects in leukocyte phagocytosis and leukotactic chemotaxis may be related to developmental immaturity of common biologic mechanisms.

Although other serum factors may be involved, it appears that the separate deficiencies of neonatal sera in generation of $\mathrm{CF}$ and enhancement of phagocytosis may both be related to deficiencies of C.3 and C.5.

The enhanced susceptibility to infection in neonates cannot be explained simply by a selective deficiency of IgM. Addition of IgM failed to correct the humoral deficiencies of chemotaxis and phagocytosis in vitro. Further, a deficiency of IgM would not explain the cellular deficiencies demonstrated. It is only by a sequential analysis of the entire inflammatory response in the neonate that these relations will become clear.

\section{Speculation}

It has become apparent that the relative susceptibility of the neonate to bacterial infections is the result of a number of deficiencies involving both humoral and cellular aspects of the neonatal inflammatory response. The future delineation of these individual defects may lead to improved therapeutic approaches in neonatal septicemia and, also, provide valuable information on the mechanisms involved in the normal inflammatory response. 


\section{Introduction}

The relative susceptibility of newborn infants to bacterial infections, particularly those of gram-negative etiology, is well known but poorly understood. Despite recent advances in antimicrobial therapy, the mortality rate in this country for infants with gram-negative septicemia approximates $50 \%$ [15].

Many investigators have attempted to cliscern the catuse of the poor clinical response of nconates to bacterial infection. In recent years, consiclerable attention has been focused upon the functional status of the neonatal response in such inflammatory events as phagocytosis $[2,4,10,13,16,18,26]$ and intracellular killing [5, 7] of ingested microorganisms. Few studies, however, have been made of the multiple factors which influence such events of the nconatal inflammatory response as margination and adherence of leukocytes to vessel walls, diapedesis to the extravascular space, and directed migration toward the infecting microorganism. The degree and rate of this migration are dependent, at least in part, upon the complement-mediated cellular response of chemotaxis [8].

In the study reported here, the cellular and humoral components of the chemotactic response in neonates were compared with those found in adults. The newborn infant was found to be deficient in both aspects of the chemotactic response. Inmune adherence activ-ity [21] was also studied and found not to differ between neonates and adults.

Table I. Comparison of chemotactic responses of neonatal PMNS and adult PMNS toward chemotactic factor generated from normal serum

\begin{tabular}{lcc}
\hline \multicolumn{1}{c}{ Generating agent } & $\begin{array}{c}\text { Neonatal } \\
\text { P.NNS/IPF }\end{array}$ & $\begin{array}{c}\text { Adult } \\
\text { PMNS/LPF }\end{array}$ \\
\hline S. aureus + serum & 2.54 & 18.7 \\
Albumin-antialbumin & 0.96 & 17.91 \\
$\quad+$ serum & 3.10 & 15.34 \\
E. coli + serum & 1.4 & 1.3 \\
Serum alone & & \\
\hline
\end{tabular}

Table 1I. Comparison of chemotactic factor generated from neonatal and normal serum ${ }^{1}$

\begin{tabular}{lcc}
\hline \multicolumn{1}{c}{ Generating agent } & $\begin{array}{c}\text { Neonatal } \\
\text { PMNS/IIPF }\end{array}$ & $\begin{array}{c}\text { Adult } \\
\text { PNNS/IPF }\end{array}$ \\
\hline S. aureus + scrum & 8.78 & 18.87 \\
Albumin-antialbumin & 6.56 & 18.87 \\
+ scrum & & \\
E. coli + serum & 7.54 & 20.03 \\
Serum alone & 1.2 & 1.7 \\
\hline
\end{tabular}

1 Normal leukocytes (PMNS) placed in all upper chambers.

\section{Materials and Methods}

\section{Leukocyte Suspensions}

Ten milliliters of heparinized (50 U.'S. P. units) venous blood were drawn from 3- to 5-day-old newborn infants who weighed at least $2500 \mathrm{~g}$ and were apparently well. Similar samples were drawn from adults in apparent good health. Leukocyte suspensions were prepared from these samples as previously described [18] with the exception that the final polymorphonuclear leukocyte (PMNS) concentration of $5 \times 10^{6} \mathrm{PMNS} / \mathrm{ml}$ was made up in standard tissue culture media (TCMI) [31]. The TCM was supplemented by the addition of fetal calf serum. Final concentration of calf serum was $10 \%$. Prior to use, all medium was heated at $56^{\circ}$ for 1 hr.

\section{Generation of Chemotactic Fictors}

Chemotatic factor (CF) was generated from fresh whole serum of neonates and adults with bacteria or an antigen-antibody complex as the stimulating agent. For bacterial stimulation, aliquots of 18-hr broth cultures of either Staphylococcus aureus or Escherichia coli were washed and resuspended to an optical density of 1.0 at $650 \mathrm{~m} \mu$. Fresh serum, $0.4 \mathrm{mI}$, was heated for 5 min at $37^{\circ}$ and then incubated with $0.4 \mathrm{ml}$ of a bacterial suspension for $5 \mathrm{~min}$ at $37^{\circ}$ followed by $30 \mathrm{~min}$ at $56^{\circ}$. Following this, the volume of the mixture was brought up to $3 \mathrm{ml}$ by the addition of TCM. For gencration of $\mathrm{CF}$ with antigen-antibody complex, a pool of rabbit anti-human albumin was heat-inactivated at $56^{\circ}$ for $60 \mathrm{~min}$. The same pool was used for all experiments. One milliliter of $5 \%$ human albumin in TCM was incubated with $0.2 \mathrm{ml}$ of the rabbit anti-human albumin at $37^{\circ}$ for $5 \mathrm{~min}$ and then at $56^{\circ}$ for $30 \mathrm{~min}$. The volume was then brought to $3 \mathrm{ml}$ by addition of TCM.

\section{Chemolactic Assay}

A modification of the Boyden assay [1] was used. A membrane $(3 \mu$ pore size) was placed in a tissue culture chamber [32]. The lower portion of the chamber was filled with a source of CF, and $0.5 \mathrm{ml}$ of a PMNS suspension was placed in the upper portion of the chamber (Fig. 1). The chamber wats then incubated at $37^{\circ}$ for $3 \mathrm{hr}$. Following incubation, the filter was removed and stained with hematoxylin and eosin [33]. The number of PMNS reaching the lowermost layer of the filter was counted in 10 fields chosen at random and expressed as the average number of cells per high power field (HPF). By varying the source of the PMINS 


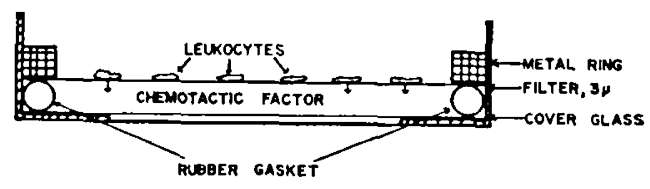

Fig. 1. Diagram of chamber used in chemotaxis experiments. For details, see text.

or the serum source of $\mathrm{CF}$, the cellular and humoral components of the chemotactic response could be individually evaluated. The method is highly reproducible using this technique (sce Results below).

\section{Immune Adherence Titers}

The procelure of Nishioka [22] was used to measure scrum complement immune adherence activity. Sensitized sheep erythrocytes were used to form the antigen-antibody-complement complex. The indicator cells were human, group $\mathrm{O}, \mathrm{Rh}^{+}$erythrocytes.

\section{Results}

The addition of $10 \%$ heat-inactivated fetal calf serum to the TCMI was found to yield more consistent results in all assays. The material was placed on both sides of the membrane to minimize the creation of a chemotactic gradient due to factors which might be generated from the calf scrum. Control preparations were run with each experiment. These consisted of TCM and fetal calf serum in the lower chamber only, and yiclded no significant chemotactic activity.

\section{Reproducibility of Method}

To demonstrate the reproducibility of the method, the chemotactic assay was performed five times on the same leukocyte suspension and source of chemotactic factor (generated with albumin-antialbumin complex). The average number of PMNS/HPF for cach of the five preparations showed close agreement (Fig. 2); furthermore, the counts of the 10 fields chosen at random in determining the average of each of the five preparations fell within a normal distribution and were arranged closely around the mean in each case.

\section{Leukocyle Ghemotaxis}

For these studies the ability of PMINS from neonates to move toward CF generated from pooled, normal scrum was compared with PMNS from adults. Each neonatal PMNS preparation was matched with a control PMINS preparation from one of a number of normal adult donors run at the same time. Nconatal leu- kocytes showed a consistent and marked deficiency in response to CF generated from S. aureus, E. coli, or albumin-antialbumin (Fig. 3).

\section{Gencration of $C F$}

In these experiments, the ability of CF generated from neonatal and adult sera to stimulate migration of a normal leukocyte suspension was compared. The data shown are those obtained with PMNS from one adult donor. These are representative of those obtaincd with PMNS from other normal adult donors. A somwhat smaller but obvious difference was seen between the amounts of effective CF generated from neonatal sera and that from adult sera (Fig. 4). The difference was also found with all three generating agents.

To rule out the possibility that neonatal PMNS

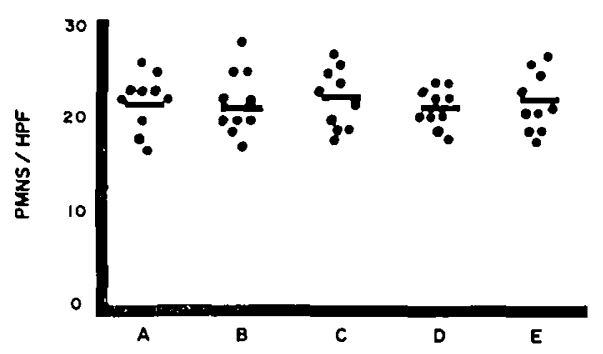

Fig. 2. Horizontal bars show the average number of PMNS/HPF for the same PMINS suspension and source of CF performed five separate times. As can be secn, these are in close agreement. Analysis of variance shows all means are from same population $\left(l^{\prime}<0.001\right)$.

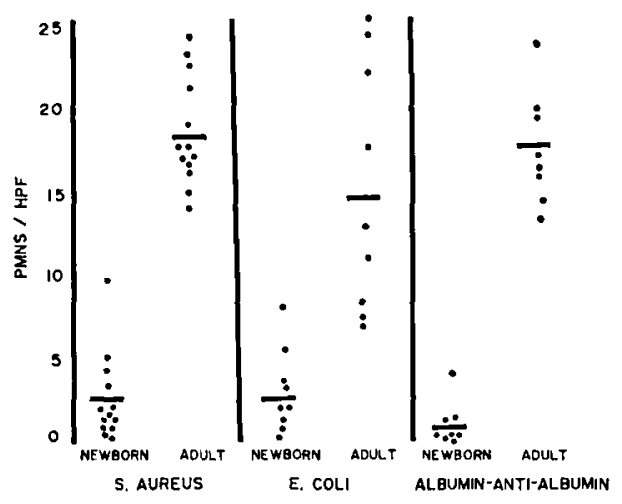

Fig. 3. Comparison between chemotactic activity of neonatal PMNS and adult PMNS. The lower portion of the chambers was filled with CF gencrated by incubation of pooled normal adult scrum with either $S$, aureus, $E$. coli, or albumin-antialbumin complexes. Control preparations consisting of either serum, $S$. aureus, E. coli, albumin-antialbumin, or TCM with $10 \%$ fetal calf serum alone all yielded less than 2.6 cells/IIPF. Horizontal bars indicate average values. 


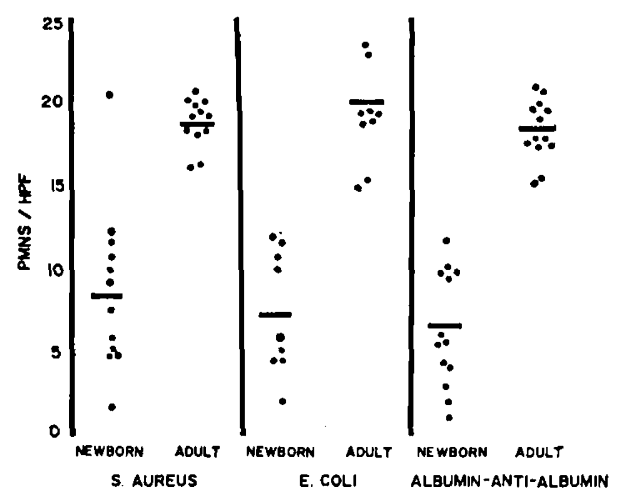

Fig. 4. Comparison between CF generated from neonatal and adult sera, by incubation with $S$, aureus, E. coli, or albumin-antialbumin. The upper portions of each chamber contained normal PMNS suspensions. Control preparations were the same as described in Figure 3, and yielded the same results. Horizontal bars indicate average valucs.

might show improved chemotactic activity in the presence of CF generated from autologous serum, several such experiments were carried out. Chemotactic response of neonatal PMNS incubated with CF generated from autologous serum was compared with that obtained when neonatal PMNS were incubated with $\mathrm{CF}$ generated from adult control serum. No improvement was seen.

\section{Immune Adherence}

No difference was found in serum complement immune adherence activity between neonatal and adult sera. Titers for both groups fell within the range of $1: 2560-1: 5120$.

\section{Discussion}

These studies demonstrate deficiencies of both the humoral and cellular components of the chemotactic response of the human neonate. The results parallel previous data reported from this laboratory which demonstrated relative deficiencies of humoral and cellular components of the phagocytic process [18]. In the earlier studies of phagocytosis, the cellular deficiency was apparent only when the experiments were carried out in dilute plasma concentrations (2.5\% or less). In the present studies, however, the cellular defect of neonatal PMNS in chemotaxis was far more apparent.

The mechanism by which leukocytes undergo chemotactic migration is presently unclear. Ward and Becker [29] have recently shown that two cell-bound serine esterases are required for cellular chemotaxis (leukotaxis). One of these esterases exists in, or on, the leukocyte in an activated state. The other is enzymati- cally inert and becomes activated following interaction with the complement system. Qualitative or quantitative deficiencies of one, or both, of these esterases might explain the deficient chemotactic response by the neonatal leukocyte.

It is possible that the cellular defects in phagocytic and leukotactic activities found in the neonatal PMNS may be related to developmental immaturity- of common biologic mechanisms. In support, Pearlman, Ward, and Becker [23] have shown, by the use of a panel of phosphonate esters, that complement-dependent erythrophagocytosis can be inhibited in a manner similar to that seen for inhibition of leukotaxis. This suggests that the same enzyme activation may be involved in both phagocytosis and chemotaxis. Bryant, DesPrez, and Rogers [3] have shown that phagocytosis may divert cellular energy stores from motility to the functions of particle ingestion and destruction. There may, thus, be a common developmental denominator for leukotactic and phagocytic activity of cells. Alternatively, however, it appears that PMNS which are deficient in chemotactic activity can exhibit normal phagocytic activity [20]. Further work is necessary to resolve these important questions.

With regard to the basis for the deficiency of neonatal serum in the generation of CF, however, more definitive data exist. Humoral enhancement of chemotaxis and phagocytosis is dependent, at least in part, on the serum complement system. Chemotactic activity has been associated with low molecular weight split products of the third (C3) [27] and fifth (C5) [24, 28] components of complement, as well as with a trimolecular complex of the fifth, sixth, and seventh components (C5, C6, C7) [30]. Enhancement of phagocytosis has been associated with activity of C3 [11, 12, 14, 21] and, more recently, with C5 $[17,19,25]$. Quantitative deficiencies of C3 and C5 have been shown in sera of normal neonates [9]. In ongoing experiments, the addition of purified C3 and C5 to sera of neonates significantly increased plagocytic and to a lesser extent chemotactic activity. While other serum factors may be involved, it appears that the separate deficiencies of neonatal sera in generation of $\mathrm{CF}$ and enhancement of phagocytosis may be related to deficiencies of C3 and C5. Since preincubation of serum at $37^{\circ}$ was part of the experimental method, it might be argued that factors involved in generating chemotactic activity are more labile in neonatal than adult serum. This seems unlikely, however, as there was no evidence of increased lability of C3 and C5 in neonatal serum upon varying the time of preincubation from 0-5 min.

The demonstration of normal serum complement 
immune adherence levels in neonatal sera is of interest, since this function involves activities of the first four complement components [6]. This finding is not incompatible with the quantitative deficiency of C3 in neonatal sera [9], since it has recently been emphasized that specific functional activities within the complement system may not be reflected by a single quantitative assay [17], and the sensitivity of the immune adherence assay is such that it can detect only a few C3 molecules per cell. Since the test is based upon twofold dilutions, however, it is unlikely that the observer will detect less than twofold differences in the C3 concentrations of different populations.

Finally, it seems clear that the enlianced susceptibility to infection in neonates cannot be explained simply by a selective deficiency of IgM. Addition of purified human myeloma IgM [33] failed to correct the humoral deficiencies of chemotaxis and phagocytosis in vitro. Further, a deficiency of IgM would not explain the cellular deficiencies demonstrated. It is only by a sequential analysis of the entire inflammatory response in the neonate that these relations will become clear. In addition to learning more of the ontogeny of the immune response, such studies will provide systems for evaluating a wide variety of therapeutic agents now used with relative ignorance in the treatment of neonatal septicemia.

Finally, it should be noted that the data presented in this paper are based upon in vitro observations. The degree to which they bear upon in vivo activity of the chemotactic response in the neonate remains to be determined.

\section{Summary}

In these studies, chemotactic function has been compared between neonates, a group with known susceptibility to bacterial infections, and adults. A modification of the Boyden in vitro assay was developed which made possible the use of human leukocytes (PMNS) and serum throughout. The humoral and cellular components of the chemotactic response were individually compared.

The data showed the following. (1) When incubated in the presence of chemotactic factor generated from stanclard pooled sera, neonatal PMNS showed significantly less chemotactic migration than adult PMNS. This was true whether the serum factor was generated from gram-positive or gram-negative bacteria or from antigen-antibody complexes. (2) When incubated in the presence of a standard PMNS suspension, neonatal serum was a much poorer source of chemotactic factor than equal amounts of adult sera. This was also true for bacterial or antigen-antibody-gencrating agents.

These data demonstrated two previously unrecognized deficiencies of the neonatal inflammatory response.

\section{References and Notes}

1. Boyden, S.: The cliemotactic effect of mixtures of antibody and antigen on polymorphonuclear leukocytes. J. Exp. Med., 115: 453 (1962).

2. Biscco, G.: Potere fagocitari del sanguc placentare fetali. G. Batteriol. Immunol., 38: 449 (1948).

3. Bryant, R. E., Desl'rez, R. M., and Rogrks, D. E.: Studies on huma leukocyte motility. II. Effects of bacterial endotoxin on leukocyte migration, adhesiveness and aggregation. Yale J. Biol. Med., 40: 192 (1967).

4. Cocchi, P., And Marianeler, L.: Phagocytosis and intracellular killing of Pseudomonas aeruginosa in premature infants. Helv. Paediat. Acta, 22: 110 (1967).

5. Coen, R., Grusi, O., AND KAUner, E.: Studies of bactericidal activity and metabolism of the lcukocyte in full-term neonates. J. P'ediat., 75: 400 (1969).

6. Coorer, N. R.: Immune allherence by the fourth component of complement. Science, 165: 396 (1969).

7. DossetT, J. H., Williams, R. C., JR., AND Quif, P. G.: Studies on interaction of bacteria, scrum factors and polymorphonu. clear leukocytes in mothers and newborns. Pediatrics, 4f: 49 (1969).

8. EBERT, R. H.: The experimental approach to inflammation. In: B. W. Zweifach, L. Grant, and R. T. McCluskey: The Inflammatory Process, pp. 1-33 (Academic Press, New York, 1965).

9. Fireman, P., Zuchowski, D. A., AND TaYlor, P. M.: Development of human complement system. J. Immunol., 103: 25 (1969).

10. Forman, M. L., AND Stiemm, E. R.: Impaired opsonic activity but normal phagocytosis in low-birth weight infants. New Engl. J. Mcd., 281: 926 (1969).

11. Gerlings-Petersen, B. T., ANd Pondman, K. W.: Erythrophagocytosis: a study of the antigen-antibody complement reaction. Vox Sang., 7: 655 (1962).

12. Gigli, I., ANd Nelson, R. A., JR.: Complement dependent immune phagocytosis. I. Requirements for $C^{\prime} 1, C^{\prime} 4, C^{\prime} 2, C^{\prime} 3$. Exp. Cell Res., 51: 45 (1968).

13. Gluck, L., AND Silverman, W. A.: Phagocytosis in premature infants. Pediatrics, 20: 951 (1957).

14. Johnston, R. B., JR., Klemperer, M. R., and Alfer, C. $\Lambda$.: The enhancement of bacterial phagocytosis by serum: the role of complement components and two cofactors. J. Exp. Med., 129: 1275 (1969).

15. Krugman, S., AND Ward, R.: Sepsis in the newborn. In: Infectious Disease of Children, pp. 199-209 (C. V. Mosby Company, St. Louis, 1968).

16. Matotir, Y.: Phagocytic and ameboid activities of the leukocytes in the newborn infant. Pediatrics, 9: 748 (1952).

17. Mit...er, M. E.: Demonstration of a major role of the fifth component of complement (C5) in the enhancement of phagocytosis (Abstract). Fed. Proc., 29: 433 (1970).

18. MILLER, M. E.: Phagocytosis in the newborn infant: humoral and ccllular factors. J. Pediat., 74: 255 (1969).

19. Mircter, M. E., ANo Nusson, U. R.: A familial deficiency of the 
phagocytosis enhancing activity of scrum related to a dysfunction of the fifth component of complement (C5). New Engl. J. Med., 282: 354 (1970).

20. Miller, M. E., Oski, F. A., ANd HARris, M. B.: Lazy lcucocyte syndrome. $\Lambda$ new disorder of neutrophil function. Lancet, i: 665 (1971).

21. NeLSON, R. A., JR.: The role of complement in immune phenomena. In: B. W. Zweifarb, L. H. Grant, and R. T. McKluskey: The Inflammatory Process, pp. 819-872 (Academic Press, New York, 1965).

22. Nisió, K.: Measurements of complement by agglutination of human erythrocytes reacting in immune-adherence. $J$. Immunol., 90: 86 (1963).

23. Pearlana, D. S., Ward, P. A., and Becker, E. L.: The requirement of serine esterase function in complement-dependent erythrophagocytosis. J. Exp. Med., 130: 745 (1969).

24. Suin, II. S., Pickering, R. J., MAyer, M. M., AND Cook, C. T.: Guinca pig C'5. J. Immunol., 101: 813 (1968).

25. Shin, II. S., SMiti, M. R., AND Wood, W. B., JR.: Heat labile opsonins to pncumoccus. II. Involvement of C3 and C5. J. Exp. Med., 130: 1229 (1969).

26. Tunicliffe, R.: Observations on anti-infectious power of blood of infants. J. Infect. Dis., 7: 698 (1910).

27. Ward, P. A.: A plasmin-split fragment of $C^{\prime} 3$ as a new chemotactic factor. J. Exp. Med., 126: 189 (1967).
28. WARD, P. A.: Complement factors involved in chemotaxis of human cosinophils and a new chemotactic factor for neutrophils from C'5. J. Inmunol., 101: 818 (1968).

29. WARD, P. A., AND BECKER, E. L.: Mechanisms of the inhibition of chemotaxis by phosphonate esters. J. Exp. Med., 125: 1001 (1967).

30. WVard, P. A., Cochirane, C. G., and Müller-Eberilard, H. J.: Further studies on the chemotactic factor of complement and its formation in vivo. Immunology, 11: 141 (1966).

31. culturSTAT medium 1066, Baltimore Biological Laboratory, Cockeysville, Mal.

32. Sykes-Moore tissue culture chamber, Bellco Glass Co., Vineland, N. J.

33. Millipore Corporation, Bedford, Mass., Techniques of Exfoliative Cytology, p. 7.

34. Pentex, Inc., Kankikce, Ill.

35. Supported by a grant from the John $\Lambda$. Hartford Foundation and by Public Health Service Career Development Award 1 KO 4 IID 25 978-01.

36. Requests for reprints should be addressed to: Micitael, E. Mill.fr, M.D., Assistant Professor of Pediatrics, University of Pennsylvania School of Medicine, 34th and Spruce Streets, Philadelphia, Penma. 19104 (USA).

37. Accepted for publication November 18, 1970. 